\title{
Effect of Leishmania major on human polymorphonuclear leucocyte function in vitro
}

\author{
A. S. AL TUWAIJRI, I. A. AL MOFLEH* and A. A. MAHMOUDt
}

Departments of Physiology, "Medicine and TParasitology, College of Medicine, King Saud University, PO Box 2925, Riyadh 11461, Saudi Arabia

\begin{abstract}
Summary. The effect of various antigens of Leishmania major promastigotes on the function of human polymorphonuclear leucocytes (PMNLs) was examined. Different concentrations of $L$. major antigens were incubated with isolated PMNLs for various periods and the respiratory burst was assessed by Luminol-dependent chemiluminescence. All the Leishmania antigens employed inhibited the PMNL respiratory burst by $35-64 \%$. PMNL viability was not affected either by the concentrations or type of the parasite antigen. Oxygen free radical scavengers enhanced the action of the antigens on the PMNL respiratory burst.
\end{abstract}

\section{Introduction}

Cutaneous leishmaniasis caused by Leishmania major is endemic in Saudi Arabia. ${ }^{1-3}$ Recently, we have shown that Leishmania promastigotes inhibit human whole blood phagocytic activity in vitro. ${ }^{4}$ The role of polymorphonuclear leucocytes (PMNLs) in host defence against a wide range of micro-organisms is well established. The microbicidal activity of PMNLs depends partly upon the generation of large quantities of oxygen free radicals (OFRs) such as superoxide anion, hydrogen peroxide, hydroxyl radicals and singlet oxygen. ${ }^{5-6}$ As the role of PMNLs in the pathogenicity of leishmaniasis is ill defined, the present study was designed to examine the effect of Leishmania and its antigens on the OFR-mediated microbicidal activity of PMNLs. Various forms of Leishmania antigens (viable, non-viable, lysate and denatured promastigotes) were incubated with human PMNLs and the effect on the oxygen-dependent respiratory burst was assessed with chemiluminescence (CL). Phorbol myristate acetate (soluble agent) and opsonised (particulate antigen) yeast were used to produce a high CL response. Combined exposure of PMNL to Leishmania and OFR scavengers such as superoxide dismutase (SOD) dimethyl sulphoxide (DMSO), sodium azide (SA) and allopurinol was also studied.

\section{Materials and methods}

\section{Parasite and antigen preparation}

L. major strain HOM/SA/1983/Sayed was isolated and

Received 11 Aug. 1989; accepted 28 Dec. 1989. maintained as described by Mahmoud et al. ${ }^{3}$ Promastigotes were collected and centrifuged, the pellet was washed twice with phosphate-buffered saline (PBS; $0.14 \mathrm{M} \mathrm{NaCl}, 2.7 \mathrm{mM} \mathrm{KCl}, 12 \mathrm{mM} \mathrm{Na} \mathrm{NPO}_{4}, 0.9 \mathrm{mM}$ $\mathrm{CaCl}_{2}$ in distilled water), and the promastigotes were counted as described previously. ${ }^{4}$ The supernate was filtered through a $22-\mu \mathrm{m}$ membrane filter (Millipore) to obtain promastigote-free lysate. Non-viable promastigotes were prepared by freezing and thawing several times. Another preparation of promastigotes was heated for $1 \mathrm{~h}$ at $90^{\circ} \mathrm{C}$ to produce denatured antigen. The protein concentration of the various antigens was determined by the method of Lowry et al. ${ }^{7}$

\section{Polymorphonuclear leucocytes}

Blood was collected by venepuncture from apparently healthy donors in sterile containers with heparin (10 IU/ $\mathrm{ml}$; Fisher Scientific Co., NJ, USA). Ten $\mathrm{ml}$ of heparinised blood was mixed with $10 \mathrm{ml}$ of Dextran T $5006 \% \mathrm{w} / \mathrm{v}$ in saline $0.9 \% \mathrm{w} / \mathrm{v}$ in a $25-\mathrm{ml}$ tube and kept at room temperature for $30 \mathrm{~min}$ before the leucocyte-rich plasma layer was removed. Erythrocytes were lysed by adding an equal volume of distilled water and the cells were then suspended in PBS. About 5-6 ml of the leucocyte rich suspension was layered over $3 \mathrm{ml}$ of Nycodenz Solution (Nyegaard and Co. AS, Torshov, Norway) in a $12-\mathrm{ml}$ tube and centrifuged at $1800 \mathrm{rpm}$ for $15 \mathrm{~min}$ to harvest PMNLs. The PMNLs were then resuspended in PBS, counted and adjusted to the desired concentrations. PMNL viability was assessed by trypan blue $(0 \cdot 1 \%)$ exclusion and only PMNL suspensions with a viability $>90 \%$ were used.

\section{Measurement of Luminol-enhanced chemiluminescence}

An LKB-Wallac 1251 luminometer with a constant temperature $\left(37^{\circ} \mathrm{C}\right)$ controller (Wallac Oy, 20101 Turku 
10, Finland) connected to an Apple Ile computer, as described by Tono-Oka et al. ${ }^{8}$ was used. Light emission was recorded in $\mathrm{mV}$. Two methods were used to quantify $\mathrm{CL}$ emission - the peak height in $\mathrm{mV}$ and the total light emission during the reaction period (area under the curve). The readings were recorded at 2-min intervals for $30 \mathrm{~min}$. The reaction mixture consisted of $100 \mu \mathrm{l}$ of PMNL suspension and $900 \mu \mathrm{l}$ medium containing $10^{-4} \mathrm{M}$ Luminol and $10^{-4} \mathrm{M}$ phorbol myristate acetate (PMA) (Sigma).

\section{Oxygen free radical scavengers}

Superoxide dismutase (SOD) (Sigma) $0.02 \mathrm{mg} / \mathrm{ml}$ and 6.6 mM dimethyl sulphoxide (DMSO; Fluka AG, Chemische Fabrik, Buchs, Switzerland), sodium azide (B.D.H. Chemicals Ltd, Poole) $0.02 \mathrm{mg} / \mathrm{ml}$ and $2 \mathrm{mM}$ allpurinol (Al Hikma, Jordan) were used as oxygen scavengers.

\section{PMNL viability}

The effect of Leishmania antigens on PMNL viability was determined by trypan blue exclusion examined after incubation for $0,30,60$ and $120 \mathrm{~min}$ at $37^{\circ} \mathrm{C}$ with the antigen preparations.

\section{Yeast opsonisation}

Bakers yeast was washed twice and resuspended in PBS and the concentration was adjusted to $2 \times 10^{8}$ particles $/ \mathrm{ml}$ and killed by boiling for $30 \mathrm{~min}$. The yeast was opsonised by incubating $100 \mu \mathrm{l}$ of autologous human serum with $900 \mu \mathrm{l}$ of yeast suspension at $37^{\circ} \mathrm{C}$ for $30 \mathrm{~min}$, washing with PBS, and was resuspended in PBS to a final concentration of $2 \times 10^{5}$ particles $/ \mathrm{ml}$.

\section{Statistical analysis}

The results of $C L$ were computed by an $L K B$ computer program that gave the $\mathrm{CL}$ maximum peak response in $\mathrm{mV}$ and the integral area under the curve of each graph. Differences between experiments with Leishmania preparations and controls were compared with the two-tailed Student's $t$-test and considered significant when $\mathrm{p}<0.05$.

\section{Results}

All the Leishmania promastigote antigens (viable, non-viable, denatured and lysate) inhibited PMNL CL. Viable and denatured promastigotes showed a significant $\mathrm{CL}$ inhibition of $64 \%$ and $68 \%$, respectively ( $p<0.001$; table I and fig. 1). The non-viable (frozen and thawed) and lysate antigens caused less inhibition. The background activity of unstimulated PMNL CL was always $<0.8 \mathrm{mV}$ and was not affected by addition of Leishmania antigen preparations. Also, there was no effect of Leishmania
Table I. Effect of various forms of $L$. major antigens on the chemiluminescence of PMNL stimulated with PMA

\begin{tabular}{|c|c|c|c|c|}
\hline \multirow{2}{*}{$\begin{array}{l}\text { Antigen } \\
\text { preparation }\end{array}$} & \multicolumn{2}{|c|}{ CL Measurement $(\mathrm{mV})$ with } & \multirow{2}{*}{$\begin{array}{l}\text { Percentage } \\
\text { inhibition }\end{array}$} & \multirow[b]{2}{*}{$\mathrm{p}$ value } \\
\hline & PBS & L. major & & \\
\hline AP & $1215 \cdot 6 \pm 31 \cdot 1$ & $442 \cdot 1 \pm 24 \cdot 1$ & 64 & 0.001 \\
\hline NP & $1038 \cdot 0 \pm 36 \cdot 2$ & $664 \cdot 9 \pm 22 \cdot 1$ & 36 & $0 \cdot 01$ \\
\hline DP & $1460 \cdot 0 \pm 77 \cdot 2$ & $460 \cdot 0 \pm 79 \cdot 9$ & 68 & 0.001 \\
\hline LP & $1337.9 \pm 97.2$ & $870 \cdot 0 \pm 37 \cdot 8$ & 35 & $0 \cdot 01$ \\
\hline
\end{tabular}

AP, Viable promastigotes; NP, non-viable promastigotes; DP denatured promastigotes; LP, promastigote lysate.

All values were expressed as the mean of six observations \pm SE. Number of promastigotes (viable or nonviable) was $1 \times 10^{\frac{1}{5}} /$ test (equivalent to $20 \mathrm{mg}$ of protein/test). PBS was used as a control. PMNLs count $5 \times 10^{5}$.

Incubation time $30 \mathrm{~min}$ at $37^{\circ} \mathrm{C}$.

Denatured promastigotes were heated at $90^{\circ} \mathrm{C}$ for $1 \mathrm{~h}$.

Percentage of CL inhibiton was calculated as follows:

Percentage CL inhibition

$$
=\frac{(\text { Control }- \text { Leishmania promastigotes })}{\text { Control }} \times 100
$$

antigen on PMNL-free media. The antigens, in the concentration used, did not induce $C L$ when added to unstimulated PMNLs.

A dose-dependent reduction in the PMNL CL response was observed with denatured Leishmania antigen (fig. 2). The maximum peak PMNL CL response was significantly reduced when PBS was replaced with different doses of denatured Leishmania antigen. When compared with non-viable promastigotes, equivalent concentrations of the

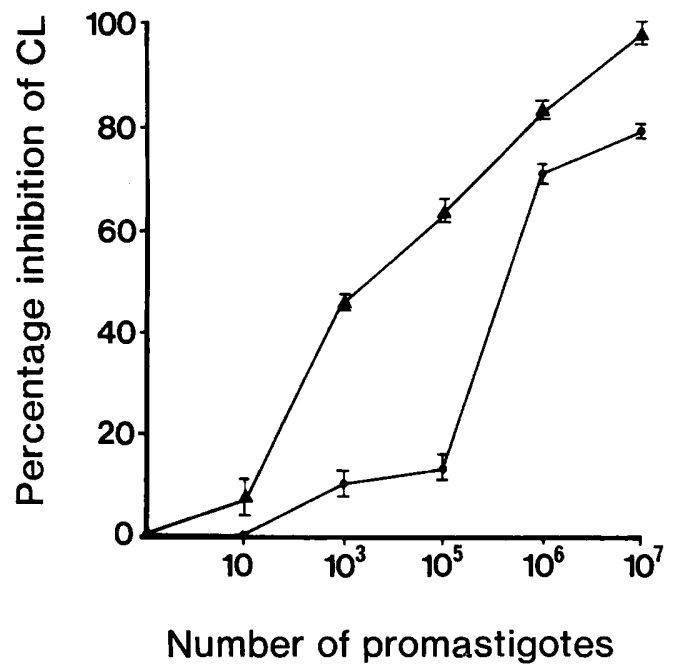

Fig. 1. Percentage inhibition of PMA-induced CL of PMNLs $\left(5 \times 10^{4}\right)$ by denatured $(\boldsymbol{\Lambda}-\mathbf{\Delta})$ and non-viable $(\mathbf{O}-\mathbf{O})$ promastigotes. 
denatured antigen preparation caused greater inhibition at all the concentrations tested (table II and fig. 3).

The maximum light output with Luminol-enhanced CL from PMNLs induced by opsonised yeast was recorded when PBS was used alone. Addition of Leishmania antigens caused a significant inhibition of $\mathrm{CL}$. The inhibitory effect of Leishmania antigens was dose-dependent (table II).

OFR scavengers-SOD, DMSO, sodium azide and allopurinol-were incubated with PMNLs in the presence or absence of Leishmania antigens. Simultaneous incubation of non-viable promastigotes and SOD significantly $(\mathrm{p}<0.05)$ inhibited PMNL CL compared with either non-viable promastigotes, or OFR scavengers alone (table III).

Incubation of Leishmania antigen with PMNLs for different lengths of time did not have any significant effect on PMNL viability. The effect of Leishmania non-viable promastigotes at the highest dose used $\left(1 \times 10^{7}\right)$ was reversible by washing the antigen from the incubation medium (table IV) with PBS.

\section{Discussion}

Earlier studies in this laboratory have shown that Leishmania major significantly inhibited phagocytosis in laboratory animals. The intravascular clearance of carbon colloid or 99 MTc sulphur colloid was markedly depressed and correlated with parasite proliferation in the liver and spleen. Furthermore, serum lysozyme, an index of macrophage activity, was reduced in infected mice. ${ }^{4,9}$

The results of the present study show that all types of Leishmania antigens (viable, non-viable, lysate and denatured) inhibit PMNL CL. More-

Table II. The effect of $L$. major antigens on CL of PMNL $\left(1 \times 10^{5}\right)$ stimulated with PMA $(100 \mu \mathrm{g} / \mathrm{ml})$ or opsonised yeast cells $\left(2 \times 10^{5} / \mathrm{ml}\right)$ after incubation for $30 \mathrm{~min}$

\begin{tabular}{|c|c|c|}
\hline \multirow{2}{*}{$\begin{array}{l}\text { Antigen preparation } \\
\text { (promastigote } \\
\text { concentration) }\end{array}$} & \multicolumn{2}{|c|}{$\mathrm{CL}$ peak response $(\mathrm{mV})$ with } \\
\hline & PMA & Opsonised yeast \\
\hline Control & $292 \cdot 4 \pm 12 \cdot 6$ & $484 \cdot 4 \pm 16 \cdot 7$ \\
\hline $\begin{array}{l}\text { Non-viable promastigotes } \\
\begin{array}{l}1 \times 10^{4} / \mathrm{ml} \\
1 \times 10^{5} / \mathrm{ml} \\
1 \times 10^{7} / \mathrm{ml}\end{array}\end{array}$ & $\begin{array}{l}240.9 \pm 7 \cdot 3 \\
80.6 \pm 5 \cdot 1 \\
58.03 \pm 2.7\end{array}$ & $\begin{array}{l}324 \cdot 4 \pm 14 \cdot 3 \\
316 \cdot 3 \pm 10 \cdot 7 \\
290 \cdot 7 \pm 9 \cdot 5\end{array}$ \\
\hline $\begin{array}{l}\text { Denatured promastigotes } \\
\begin{array}{l}1 \times 10^{4} \\
1 \times 10^{5} \\
1 \times 10^{7}\end{array}\end{array}$ & $\begin{array}{r}92.8 \pm 8.4 \\
44.9 \pm 5.3 \\
9.8 \pm 14.7\end{array}$ & $\begin{array}{l}300 \cdot 9 \pm 6 \cdot 7 \\
296 \cdot 9 \pm 11 \cdot 3 \\
271 \cdot 5 \pm 8 \cdot 0\end{array}$ \\
\hline
\end{tabular}

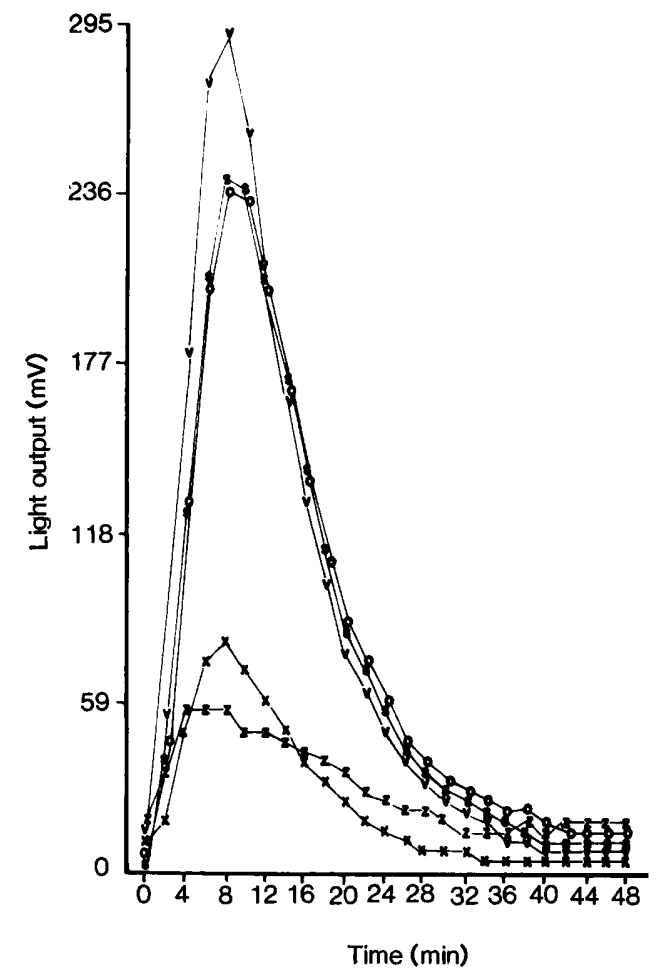

Fig. 2. Inhibition of PMA-induced CL of PMNLs $\left(5 \times 10^{4}\right)$ by various concentrations of denatured promastigotes: $1 \times 10^{3}(\mathrm{~S}$ $\mathrm{S}), 1 \times 10^{5}(\mathrm{O}-\mathrm{O}), 1 \times 10^{6}(\mathrm{X}-\mathrm{X}), 1 \times 10^{7}(\mathrm{Z}-\mathrm{Z})$ and control (V-V).

over, this inhibitory effect is dose-dependent and is directly proportional to antigen concentration expressed either as the number of promastigotes or the protein concentration. The inhibition of PMNL respiratory burst by denatured Leishmania antigen was shown to be reversible after the antigen was removed from the incubation medium. Promastigotes denatured by heat exhibited a greater inhibitory effect than either the viable or non-viable promastigotes. It is suggested that the heating enhanced the release of factor(s) that induced the inhibitory effect on the PMNLs. When the antigen was boiled for $1 \mathrm{~h}$, it was still potent enough to exert a marked inhibitory effect on PMNLs, indicating that the inhibitory factor(s) of the parasite are heat stable.

As well as macrophages, PMNLs are considered to be important in generating OFRs as a part of their microbicidal activities. ${ }^{5,6}$ Co-culturing of PMNLs with any one of the OFR scavengers (SOD, DMSO, azide, or allupurinol) plus non-viable promastigotes as used in the present study, significantly enhanced the inhibitory effect on PMNL CL in comparison with either OFR scavengers or the 
Table III. Effect of OFR scavengers on inhibition of PMNL CL by Leishmania non-viable promastigotes

\begin{tabular}{|c|c|c|c|c|}
\hline \multirow[b]{2}{*}{$\begin{array}{c}\text { OFR } \\
\text { scavenger }\end{array}$} & \multicolumn{2}{|c|}{ Control (PBS) preparation } & \multicolumn{2}{|c|}{ Preparations with non-viable promastigotes $\dagger$} \\
\hline & $\begin{array}{l}\text { Mean }(\mathrm{SE}) \text { CL peak } \\
\text { response }(\mathrm{mV})\end{array}$ & $\begin{array}{c}\mathrm{CL} \\
\text { inhibition }(\%)\end{array}$ & $\begin{array}{l}\text { Mean }(\mathrm{SE}) \mathrm{CL} \text { peak } \\
\text { response }(\mathrm{mV})\end{array}$ & $\begin{array}{c}\mathrm{CL} \\
\text { inhibition }(\%)\end{array}$ \\
\hline PBS (control) & $1393 \quad(141)$ & $\ldots$ & $646 \cdot 6(18 \cdot 2)$ & 54 \\
\hline $\operatorname{SOD}(0.02 \mathrm{mg} / \mathrm{ml})$ & $488.42(180)$ & 62 & $323 \cdot 47(97 \cdot 8) \ddagger$ & 77 \\
\hline $\operatorname{DMSO}(6.6 \mathrm{mM})$ & $948 \cdot 3(130)$ & 32 & $521 \quad(12 \cdot 7) \S$ & 63 \\
\hline Sodium azide $(0.02 \mathrm{mg} / \mathrm{ml})$ & $87 \cdot 8(31)$ & 94 & $63.2(17.9)$ & 95 \\
\hline Allopurinol $(2 \mathrm{~mm})$ & $977.7(40)$ & 30 & $691.6(1.2) \S$ & 50 \\
\hline
\end{tabular}

* Percentage CL inhibition $=\frac{\text { Control }(\mathrm{PBS}) \mathrm{CL}-\text { Leishmania promastigote } \mathrm{CL}}{\text { control } \mathrm{CL}} \times 100$.

$\dagger$ Non-viable promastigote protein $20 \mathrm{mg} /$ test $;$ PMNL count $5 \times 10^{5} / \mathrm{ml}$; incubation time, $30 \mathrm{~min}$; temperature, $37^{\circ} \mathrm{C}$.

$\ddagger \mathrm{p}<0.01$.

$\S \mathrm{p}<0.001$.

parasite antigen alone. This potentiation between the antigen and OFRs on the inhibition of PMNL $\mathrm{CL}$ responses suggests that either Leishmania antigen does not interfere with OFR scavengers or that a certain component of the parasitic antigen may possess a factor that acts in a fashion similar to OFR scavengers. This phenomenon was observed with malaria in which the survival of the

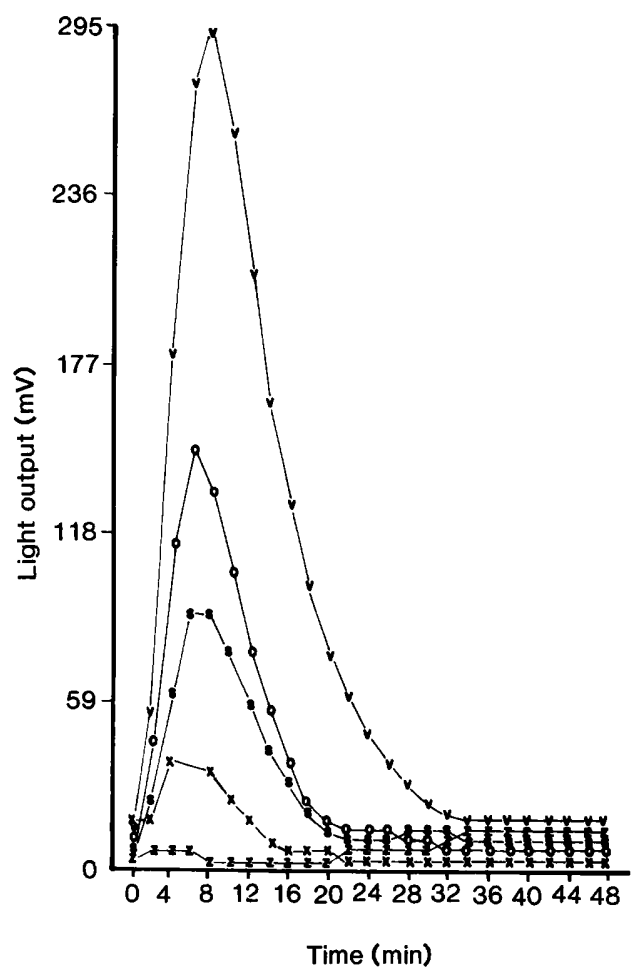

Fig. 3. Inhibition of PMA-induced CL of PMNLs $\left(5 \times 10^{4}\right)$ by various concentrations of non-viable promastigotes: $1 \times 10^{3}(\mathrm{~S}-$ $\mathrm{S}), 1 \times 10^{5}(\mathrm{O}-\mathrm{O}), 1 \times 10^{6}(\mathrm{X}-\mathrm{X}), 1 \times 10^{7}(\mathrm{Z}-\mathrm{Z})$ and control (V-V). parasite intracellularly is partly attributed to the indigenous OFR scavenger content of the plasmodia. ${ }^{10,11}$ Furthermore, the toxic effect of the Leishmania parasite on PMNLs could be a direct action on the cell membrane or at the level of the intracellular organelles. Generation of OFRs by PMNLs stimulated with PMA is reported to be through specific receptors, e.g., phospholipid-dependent kinase, protein kinase $C .{ }^{12,13}$ In the light of this, it could be stated that the inhibitory action of $L$. major antigens on the PMA-induced respiratory burst observed in this study is probably due to interference with PMA binding to protein kinase receptors. On the other hand, the source of oxygen reactive metabolites produced by PMNLs following stimulation with opsonised particles (yeast or Zymosan) is believed to be due to the activation of receptors of the alternative complement pathways. ${ }^{14}$

In conclusion, we suggest that PMNLs may play some role in the pathogenicity of Leishmania parasites.

Table IV. The effect on the Luminol-dependent CL PMNLs stimulated with PMA of washing $L$. major nonviable promastigote antigen from the incubation medium with PBS

\begin{tabular}{lc}
\hline \multicolumn{1}{c}{ CL reaction mixture } & $\begin{array}{c}\text { Mean (SE) CL } \\
\text { peak response (mV)* }\end{array}$ \\
\hline Control (PMNL + PBS), not washed & $1120 \cdot 1(2 \cdot 2)$ \\
PMNL + Leishmania antigen (not washed) & $537 \cdot 2(10 \cdot 7)$ \\
Control (PMNL + PBS), washed & $1235 \cdot 2(7 \cdot 4)$ \\
PMNL + Leishmania antigen (washed) & $1197 \cdot 3(20 \cdot 0)$ \\
\hline
\end{tabular}

Non-viable promastigotes and PMNL counts were $1 \times 10^{5} /$ test; incubation time $30 \mathrm{~min}$.

* Data are expressed as mean (SE) of four observations. 


\section{REFERENCES}

1. Al Gindan Y, Abdul Aziz O, Kubba R. Cutaneous leishmaniasis in Al-Hassa, Saudi Arabia. Int J Dermatol 1984; 23: 194-197.

2. Hussein M F. Leishmaniasis diseases in Saudi Arabia. Arab Biological Union: a Seminar on Leishmaniasis in Arabic Countries; Amman, Jordan. 15-17 June 1981.

3. Mahmoud A A, Al-Tuwaijri A S, Al-Mofleh I A, AlKhuwaitir S A. In vitro and in vivo isolation of Leishmania tropica from Saudi Arabia. Zeit Parasitenk $1985 ; 71: 271-272$.

4. Al-Mofleh I, Al-Tuwaijri A, Mahmoud A. Effect of Leishmania major on Luminol-dependent chemiluminescence of whole blood phagocytosis. Trop Med Parasitol. (In press).

5. Babior B M. Oxygen-dependent microbial killing by phagocytes. New Eng J Med 1978; 298 : 659-668.

6. Klebanof S J. Oxygen-dependent cytotoxic mechanisms of phagocytes. In: Gallin J I, Fauci A S (eds) Advances in host defense mechanisms, vol 1. New York, Raven Press. 1982: 111-162.

7. Lowry $\mathrm{O} \mathrm{H}$, Rosebrough $\mathrm{N} \mathbf{J}$, Farr A L, Randall R J. Protein measurement with the folin phenol reagent. $J$ Biol Chem 1951 ; 193 : 265-275.
8. Tono-Oka T, Ueno N, Matsumoto T, Ohkawa M, Matsumoto S. Chemiluminescence of whole blood. I. A simple and rapid method for the estimation of phagocytic function of granulocytes and opsonic activity in whole blood. Clin Immunol Immunopathol 1983; 26: 66-75.

9. Al-Mofleh I A. A macrophage immunosuppression induced by Leishmania major in BALB/c mice. Trop Med Parasitol 1987; 38: 93-96.

10. Suthipark U, Krungkrai J, Jearnpipatkul A, Yuthavong Y, Panijpan B. Superoxide dismutase (SOD) in mouse red blood cells infected with Plasmodium berghei.J Parasitol 1982; 68: 337-339.

11. Arias A E, Waiter R D. Plasmodium falciparum: association with erythrocytic superoxide dismutase. $J$ Protozool $1988 ; 35$ : 348-351.

12. Niedel J E, Kuhn L J, Vandenbark G R. Phorbol diester receptor copurifies with protein kinase C. Proc Natl Acad Sci USA 1983; 80: 36-40.

13. Chung T, Kim Y B. Two distinct cytolytic mechanisms of macrophages and monocytes activated by phorbol myristate acetate. J Leukoc Biol 1988; 44: 329-336.

14. Roos D, Bot A A M, Van Schaik M L J, De Beer M, Daha M R. Interaction between human neutrophils and zymosan particles: the role of opsonins and divalent cations. J Immunol 1981 ; 126 : 433-440. 